\title{
Circadian rhythms in blood pressure in free-ranging three-toed sloths (Bradypus variegatus)
}

D.P.F. Duarte, V.L. Silva, A.M. Jaguaribe, D.P. Gilmore and C.P. Da Costa
Departamento de Fisiologia e Farmacologia, Universidade Federal de Pernambuco, Recife, PE, Brasil
Correspondence

D.P.F. Duarte

Departamento de Fisiologia

e Farmacologia, UFPE

Av. Professor Morais Rego, s/n

50670-901 Recife, PE

Brasil

Fax: +55-81-3271-8530

E-mail: dfittipaldi@bol.com.br

Presented at the 34th International Congress of Physiological Sciences, Christchurch, New Zealand, August 2001.

Research supported by the Fundação de Amparo à Ciência e Tecnologia do Estado de Pernambuco (FACEPE).

Received January 4, 2002 Accepted September 30, 2002

\begin{abstract}
Blood pressure (BP) profiles were monitored in nine free-ranging sloths (Bradypus variegatus) by coupling one common carotid artery to a BP telemetry transmitter. Animals moved freely in an isolated and temperature-controlled room $\left(24^{\circ} \mathrm{C}\right)$ with $12 / 12$-h artificial light-dark cycles and behaviors were observed during resting, eating and moving. Systolic (SBP) and diastolic (DBP) blood pressures were sampled for $1 \mathrm{~min}$ every $15 \mathrm{~min}$ for $24 \mathrm{~h}$. BP rhythm over $24 \mathrm{~h}$ was analyzed by the cosinor method and the mesor, amplitude, acrophase and percent rhythm were calculated. A total of 764 measurements were made in the light cycle and 721 in the dark cycle. Twenty-four-hour values (mean $\pm \mathrm{SD})$ were obtained for SBP $(121 \pm 22 \mathrm{mmHg})$, DBP $(86 \pm 17$ $\mathrm{mmHg}$ ), mean $\mathrm{BP}(\mathrm{MBP}, 98 \pm 18 \mathrm{mmHg})$ and heart rate $(73 \pm 16 \mathrm{bpm})$. The SBP, DBP and MBP were significantly higher (unpaired Student $t$-test) during the light period $(125 \pm 21,88 \pm 15$ and $100 \pm 17 \mathrm{mmHg}$, respectively) than during the dark period $(120 \pm 21,85 \pm 17$ and $97 \pm$ $17 \mathrm{mmHg}$, respectively) and the acrophase occurred between 16:00 and 17:45 h. This circadian variation is similar to that observed in cats, dogs and marmosets. The BP decreased during "behavioral sleep" (MBP down from $110 \pm 19$ to $90 \pm 19 \mathrm{mmHg}$ at 21:00 to 8:00 h). Both feeding and moving induced an increase in $\operatorname{MBP}(96 \pm 17$ to $119 \pm 17$ $\mathrm{mmHg}$ at $17: 00 \mathrm{~h}$ and $97 \pm 19$ to $105 \pm 12 \mathrm{mmHg}$ at 15:00 h, respectively). The results show that conscious sloths present biphasic circadian fluctuations in BP levels, which are higher during the light period and are mainly synchronized with feeding.
\end{abstract}

Sloths, mammals belonging to the family Bradypodidae, inhabit the tropical forests of Central and South America. They are of particular interest to researchers because of their low pattern of motor activity as well as their extremely slow movement. The sloths' curious postural behavior can be clearly observed during most of the time when they remain suspended from the branches of trees.

Previous measurements of blood pres-
Key words

- Sloths

- Bradypus

- Circadian rhythm

- Blood pressure sure (BP) in unanesthetized sloths have been carried out in laboratory situations with the animals placed in an experimental chair (1$6)$. In these studies, BP levels were lower than those recorded by Johansen et al. (7) in immobilized but unanesthetized sloths. The cardiovascular adjustments to tilting $(1,2,5)$ and the BP and heart rate (HR) responses to the injections of catecholamines and autonomic drugs $(4,6)$ were exaggerated and quali- 
tatively different in comparison with those observed in other mammals. Increases (1) or falls (3) in BP were observed in response to the approach used by different investigators, showing the sensitivity of these species to the presence of humans.

A circadian rhythm in BP has been demonstrated in various species of mammals, including rats $(8,9)$, rabbits (9), cats (10), dogs (11), marmosets (12) and mice (13). These studies have contributed to a better understanding of the behavior and physiology of these animals.

In the present study we used biotelemetry to examine BP changes in free-ranging sloths (Bradypus variegatus) to determine the pattern of circadian rhythms during an artificial light-dark cycle, and how the cardiovascular system of these animals is affected by changes in behavior in the absence of direct human influence. Biotelemetry is an extremely valuable research tool which can be used to study unanesthetized animals over a prolonged period of time without the interference of an investigator.

Biotelemetric measurements of BP were recorded in adult sloths $(4.4 \pm 0.6 \mathrm{~kg})$, four males and two females, over a period of $48 \mathrm{~h}$ and in three males over a period of $26 \mathrm{~h}$. A total of 1485 recordings were obtained, each lasting $1 \mathrm{~min}$. In the latter three males, the trials were interrupted for technical reasons (clotting and loss of the BP signal).

Sloths were obtained from the wild in the vicinity of Recife, PE, Brazil, and kept in the vivarium at the university for two weeks before being used. The animals were observed and weighed daily and the different aspects of their behavioral repertoire were noted as described by Silva (14) for freeranging sloths. This included postural habit, as well as feeding and motor activity. On the day prior to surgery the animals were shaved in the appropriate regions for placement of silver plate electrodes to record the electrocardiogram (ECG) in lead II as described by Duarte et al. (1). Records of ECG were uti- lized as an index of postsurgical stress.

Sloths have a rete mirabile in their limbs which prevents the use of peripheral cannulation for BP studies. Therefore, the surgical technique described by Duarte et al. (1) was utilized for cannulation of the common carotid artery. Under local anesthesia with 10 $\mathrm{ml} \mathrm{2 \%} \mathrm{xylocaine} \mathrm{(Astra} \mathrm{Química} \mathrm{do} \mathrm{Brasil,}$ São Paulo, SP, Brazil), a midline incision was made in the anterior neck region and the right common carotid artery was isolated and cannulated. The catheter was filled with heparinized physiological saline (Liquemine, Produtos Roche e Químicos e Farmacêuticos, Rio de Janeiro, RJ, Brazil).

Twenty-four hours after surgery the animals were dressed in a jacket with a pocket in which the BP telemetry transmitter was placed. The transmitter, previously calibrated, was attached to an arterial catheter and the animals were able to roam freely in an experimental room with controlled 12/12-h artificial light/dark cycles (lights on at 6:00 h). The room had dimensions of $4.5 \times 3.0 \times 3.5$ $\mathrm{m}$ and had a large branched tree trunk in the middle of the floor which was available for climbing and moving. Ambient temperature was maintained at $24^{\circ} \mathrm{C}$. Water and food (fresh embauba leaves) were available $a d$ libitum. The BP signals, sampled at $200 \mathrm{~Hz}$, were collected for $1 \mathrm{~min}$ at intervals of 15 min for a 24-h period. Animals were observed for behavioral activity (resting, eating and moving) through a unidirectional visor placed in the experimental room. Resting behavior was classified in one of two ways, as defined by Moura Filho et al. (15) from their studies on sleep-wake cycles in $B$. variegatus. These were a) "awake-alert" with the head raised, the eyes open and showing occasional blinks, and b) "behavioral sleep" during which the animal remained suspended, or else seated with the head raised and the eyes closed or with the head down on the chest and encircled by one or both of the forelimbs. Feeding behavior was defined as spontaneously eating fresh embauba leaves. 
Moving behavior was recorded when the animal was moving along the branches of the trees or dragging itself forward on the ground.

Systolic (SBP) and diastolic (DBP) blood pressures were calculated heartbeat to heartbeat using the Windaq 200 Calculate software (Dataq Instruments, Akron, OH, USA) and presented in Excel software. Mean BP (MBP) was calculated as DBP plus one third of the difference between SBP and DBP. The data are reported as means \pm SD.

Statistical analysis was performed by twoway ANOVA for comparisons of the mean levels of SBP, DBP and MBP on different experimental days and of individual mean values for each animal, i.e., each animal represents one group of values. The Tukey test was used to determine significant differences between groups.

The COSANA software was used to analyze BP rhythms and a cosine curve was constructed using the cosinor method (the least square cosine fitting) as modified by Benedito-Silva (16), to show patterns of changes in BP over $24 \mathrm{~h}$. The fitted period was set at $24 \mathrm{~h}$, and the mesor (midlineestimating statistic of rhythm, overall 24-h mean) and amplitude (one half of the total cosine excursion) were calculated.

Statistical significance of the difference in mean HR before and after surgery and of the measurements of SBP, DBP and MBP related to the dark-light cycle was determined by the Student $t$-test. The level of significance was defined at $\mathrm{P}<0.05$. At the conclusion of the study, the cannulae were removed and, after a period of recovery, the sloths were released back into the wild.

The animal experiments were carried out with previous approval of the Ethics Committee of Centro de Ciências Biológicas, Universidade Federal de Pernambuco and with license from Instituto Brasileiro de Meio Ambiente (IBAMA, No. 075/98-DIFAS).

Mean HR values before $(70 \pm 17 \mathrm{bpm})$ and after $(73 \pm 16 \mathrm{bpm})$ surgery were not significantly different $(\mathrm{P}>0.05$, paired Stu- dent $t$-test), suggesting that the animals were unstressed.

Mean SBP, DBP and MBP values during the experimental period were $121 \pm 22,86 \pm$ 17 and $98 \pm 18 \mathrm{mmHg}$, respectively. These levels did not change significantly during the days of experimentation $\left(\mathrm{P}>0.05, \mathrm{~F}_{(2.1482)}=\right.$ 1.69). The comparative statistical analysis of individual MBP values showed that they differed from one another $\left(\mathrm{F}_{(8.1476)}=201.80\right.$, $\mathrm{P}<0.001$ for SBP, $\mathrm{F}_{(8.1476)}=211.70, \mathrm{P}<0.01$ for DBP and $F_{(8.1476)}=214.76, P<0.001$ for MBP), although only one male exhibited high SBP (151 $\pm 14 \mathrm{mmHg})$, DBP (102 \pm 8 $\mathrm{mmHg})$ and MBP $(125 \pm 9 \mathrm{mmHg})$ in comparison to the other eight sloths $(\mathrm{P}<0.001$, Tukey test). However, these values could not be explained by any aberrant behavior, since the behavior of this animal was similar to that observed in the others.

The present findings demonstrate that the levels of BP in free-ranging B. variegatus were similar to those obtained by Duarte et al. (1) in sloths kept in an experimental chair and to those found in other mammals including rats $(8,9)$, cats $(10)$ and dogs $(11)$, but higher than measured in rabbits (9). While differences were recorded between individual sloths, the overall changes in BP levels over $24 \mathrm{~h}$ showed similar patterns throughout the period of monitoring.

Although various aspects of the physiology and behavior of the animal do change over time, certain patterns of rhythmicity are apparent. These are generated by the body's internal clock, which acts to ensure that the different physiological systems will always function at optimal levels. Among the various external stimuli, termed synchronizers or zeitgebers, that entrain the endogenous circadian rhythms of BP, the most important is the light-dark cycle (17).

In the present study the levels of BP recorded in sloths over a 2-day period revealed clear circadian variation (Figure 1). Spontaneous variations (increase and decrease) in BP levels occurred without any 
Figure 1. Variations correlated with time of day in systolic (SBP), diastolic (DBP) and mean (MBP) blood pressure in unanesthetized sloths, Bradypus variegatus, over a period of two days. evident relationship to external stimuli. These changes showed that there was ample fluctuation in BP levels over $24 \mathrm{~h}$. As can be seen in Figure 1, the standard deviation of SBP was larger than that of DBP and MBP, showing greater lability of this parameter. BP levels were significantly higher $(\mathrm{P}<0.05$, unpaired Student $t$-test) in the light than in the dark period (SBP, $125 \pm 21$ vs $120 \pm 21$ mmHg; DBP, $88 \pm 15$ vs $85 \pm 17 \mathrm{mmHg}$, and MBP, $100 \pm 17$ vs $97 \pm 17 \mathrm{mmHg}$, respectively). Higher BP levels have been observed during the light period in cats (10), dogs (11), and marmosets (12), and during the dark period in rats and rabbits (9). Thus, Bradypus presents a clear circadian variation of BP similar to that recorded in the former three groups of mammals.

The cosine curve, for SBP, DBP and MBP (Figure 2) showed a mesor value (mean $\pm \mathrm{SEM})$ of $121 \pm 0.8,90 \pm 0.6$ and $104 \pm 0.6$ $\mathrm{mmHg}$, amplitude of $14 \pm 1,11 \pm 0.8$ and 12
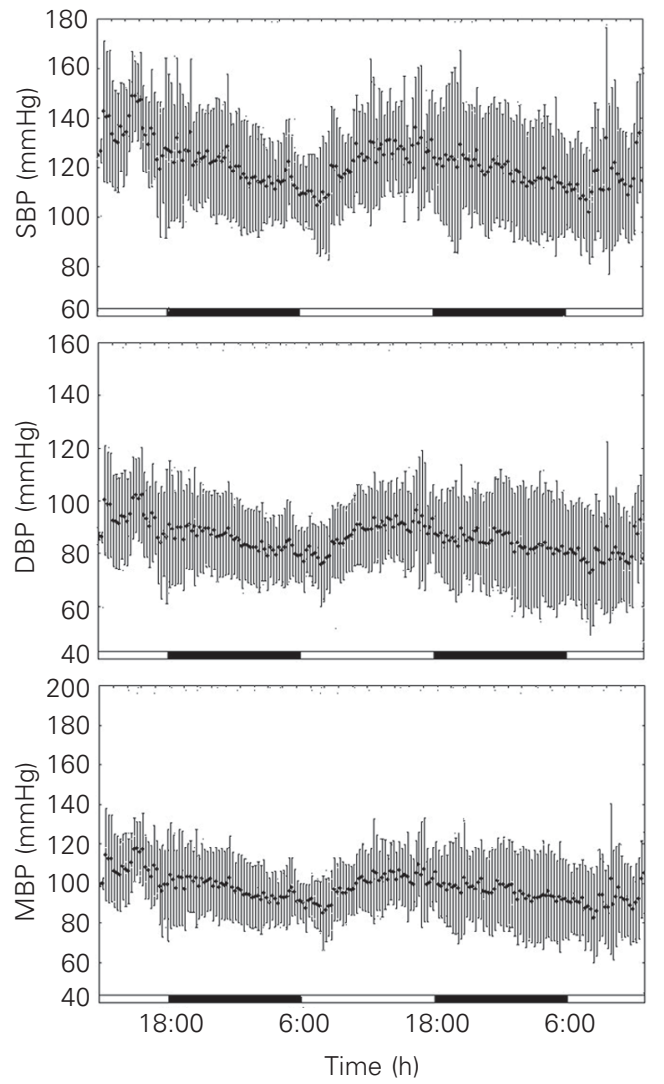

$\pm 0.9 \mathrm{mmHg}$, an acrophase value of 16:32 \pm $0: 22,17: 13 \pm 0: 34$ and 16:54 $\pm 0: 28 \mathrm{~h}$, and $\mathrm{a}$ percent rhythm of 32, 36 and 34\%, respectively. The mesor levels are similar to those obtained in rats, but higher than those found in rabbits (9). However, the SBP and DBP amplitudes were around four- and three-fold higher, respectively, than those observed in both of these species (SBP: $3.3 \pm 0.3 \mathrm{mmHg}$ for rabbits and $3.1 \pm 0.3 \mathrm{mmHg}$ for rats; DBP: $2.8 \pm 0.2 \mathrm{mmHg}$ for rabbits and $3.6 \pm$ $0.2 \mathrm{mmHg}$ for rats) showing a lability in their levels in $B$. variegatus.

In mammals, the diurnal and nocturnal patterns of BP result from neuroendocrine changes associated with alterations in mental and physical activity over a $24-\mathrm{h}$ period. In diurnally active mammals BP is higher during the day, falling at night during sleeping (18). Observations on sloths during the present study showed that different bouts of behavior occupied their time as follows: "behavioral sleep" (67\%), "awake-alert” (24\%), feeding $(7 \%)$, and moving $(2 \%)$. "Behavioral sleep" was observed during both the light and dark periods, but predominated in the latter; "awake-alert", eating and moving were more common during the former. "Behavioral sleep" showed the highest incidence between 21:00 and 8:00 h, eating at 17:00 h, and moving at 15:00 h. "Behavioral sleep" was accompanied by a fall in BP (MBP down from $110 \pm 19$ to $90 \pm 19 \mathrm{mmHg}$; $\mathrm{P}<0.05$, unpaired Student $t$-test). Both feeding and moving increased BP (MBP up from $96 \pm 17$ to $119 \pm 17 \mathrm{mmHg}$ during eating, and from $97 \pm 19$ to $105 \pm 12 \mathrm{mmHg}$ during moving; $\mathrm{P}<0.001$, paired Student $t$-test).

Among the several investigators who have studied biological and behavioral rhythms in sloths, there are divergences of opinion related to the motor activity pattern and sleep duration of these animals (14). Previous studies by Sunquist and Montgomery (19) indicated that the genus Bradypus does not have a cyclic pattern of diurnal and nocturnal activity, although a reduction in activity was 
observed at the end of the dark period. They suggested that this behavior resulted from a decrease in ambient temperature at that time. Studies evaluating sleep patterns in sloths through the electroencephalogram demonstrated that they sleep about $16 \mathrm{~h}$ per day, including the period of early morning (15). In the present study we observed that, although BP levels were highest during the light period (with the acrophase occurring between 16:00 and 17:45 h), the batiphase was also recorded during the same period $(7: 30 \mathrm{~h})$. This suggests that these animals may be sleeping at this time, since sleep is known to be associated with a significant reduction in $\mathrm{BP}$; however, room temperature remained constant at $24^{\circ} \mathrm{C}$, thus precluding any effect of changes in ambient temperature on activity.

The present experiments on free-ranging sloths (B. variegatus) demonstrate the existence of a biphasic circadian fluctuation in BP with the highest level observed during the light period. The fact that this occurred on successive days indicates that the animals were chronobiologically adjusted to the experimental conditions. The acrophase of BP, occurring during the light period between 16:00 and $17: 45 \mathrm{~h}$, seems to be synchronized mainly with feeding (17:00 h). Although a circadian rhythm in BP was clearly demonstrated, the existence of others not examined in the present study, such as an ultradian rhythm (probably involved in BP lability) or perhaps an infradian rhythm, cannot be ruled out.
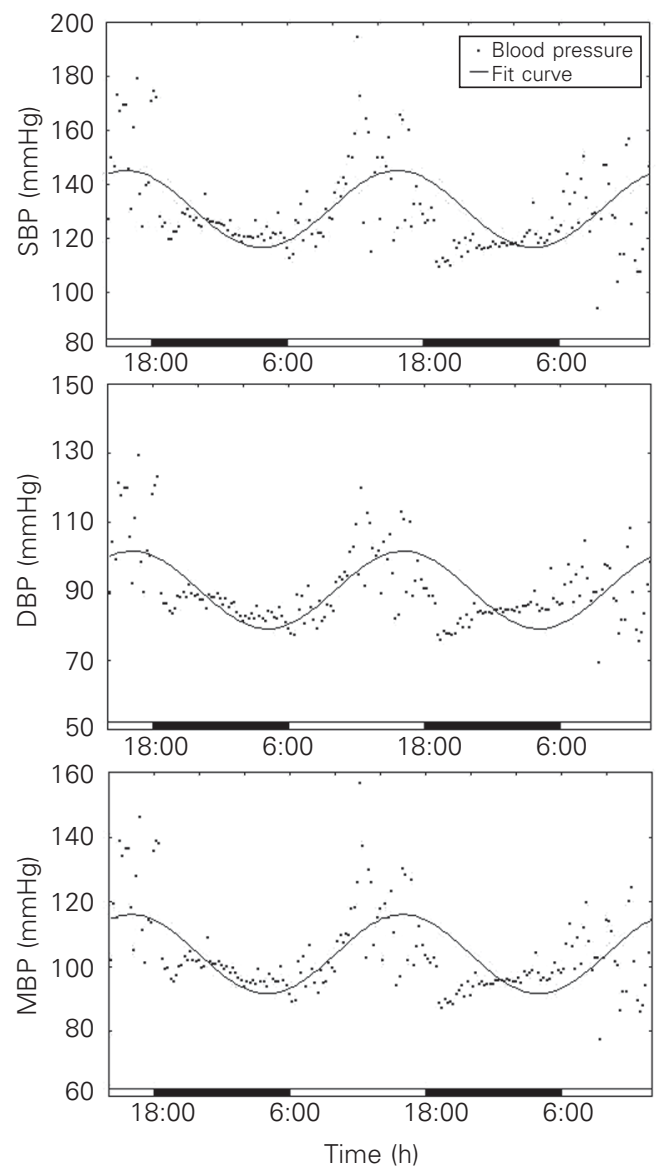

Figure 2. A cosine curve, constructed using COSANA software, illustrating the circadian rhythm in mean (MBP), diastolic (DBP) and systolic (SBP) blood pressure in one representative free-ranging sloth, Bradypus variegatus, over a period of two days. The line indicates the cosine fit and the points indicate the individual values of blood pressure.

\section{Acknowledgments}

Special thanks are due to the students André Vieira, Ana Katarina Gomes and Dinani Matoso for technical assistance.

\section{References}

1. Duarte DPF, Da Costa CP \& Huggins SE (1982). The effects of posture on blood pressure and heart rate in the three-toed sloth (Bradypus tridactylus). Comparative Biochemistry and Physiology, 73A: 697-702.

2. Duarte DPF, Da Costa CP \& Huggins SE (1983). The autonomic component in blood pressure and heart rate: effects of tilting in the three-toed sloth. Comparative Biochemistry and Physiology, 74C: 485-492.

3. Duarte DPF, Da Costa CP \& Huggins SE (1986). Hypotensive bout in the sloth (Bradypus tridactylus): a possible pattern response to stress. Brazilian Journal of Medical and Biological Research, 19: 519a (Abstract).

4. Duarte DPF, Huggins SE, Da Costa CP \& Leal AM (1987). Responses of the three-toed sloth, Bradypus tridactylus, to some commonly used pharmacologic agents. I. Autonomic drugs. Comparative Biochemistry and Physiology, 88C: 275-285.

5. Duarte DPF, Huggins SE, Da Costa CP \& Leal AM (1989). The effects of posture changes on blood pressure and heart rate of anesthetized and reserpinized sloths. Comparative Biochemistry and Physiology, 94A: 159-165. 
6. Duarte DPF, Huggins SE, Da Costa CP \& Leal AM (1989). Responses of the three-toed sloth, Bradypus tridactylus, to some commonly used pharmacologic agents. II. Chloralose and reserpine. Comparative Biochemistry and Physiology, 92C: 405-411.

7. Johansen K, Martin AW \& Sawaya P (1966). Some circulatory characteristics of the three-toed sloth Bradypus tridactylus. Anais da Academia Brasileira de Ciências, 38: 543-551.

8. Van Den Buuse M (1994). Circadian rhythms of blood pressure, heart rate, and locomotor activity in spontaneously hypertensive rats as measured with radio-telemetry. Physiology and Behavior, 55: 783-787.

9. Sato K, Chatani F \& Sato S (1995). Circadian and short-term variabilities in blood pressure and heart rate measured by telemetry in rabbits and rats. Journal of the Autonomic Nervous System, 54: 235246.

10. Brown SA, Langford K \& Tarver S (1997). Effects of certain vasoactive agents on the long-term pattern of blood pressure, heart rate, and motor activity in cats. American Journal of Veterinary Research, 58: 647-652.

11. Mishina M, Watanabe $T$, Matsuoka S, Shibata K, Fujii K, Maeda H \& Wakao Y (1999). Diurnal variations of blood pressure in dogs. Journal of Veterinary Medical Sciences, 61: 643-647.

12. Schnell CR \& Wood JM (1993). Measurement of blood pressure and heart rate by telemetry in conscious, unrestrained marmosets.
American Journal of Physiology, 33: H1509-H1516.

13. Gross V, Milia AF, Plehm R, Inagami T \& Luft FC (2000). Long-term blood pressure telemetry in AT2 receptor-disrupted mice. Journal of Hypertension, 18: 955-961.

14. Silva VL (1999). Contribuição ao estudo dos comportamentos e ritmos biológicos em preguiças, Bradypus variegatus. Doctoral thesis, Centro de Ciências Biológicas, Universidade Federal de Pernambuco, Recife, PE, Brazil.

15. Moura Filho AG, Huggins SE \& Lins SG (1983). Sleep and waking in the three-toed sloth, Bradypus tridactylus. Comparative Biochemistry and Physiology, 76A: 345-355.

16. Benedito-Silva AA (1988). Metodologia de análise matemática e estatística dos ritmos biológicos. In: Cipolla-Neto J, Marques N \& Menna-Barreto LS (Editors), Introdução ao Estudo da Cronobiologia. Ícone Editora, São Paulo, SP, Brazil, 50-61.

17. Marques N \& Menna-Barreto L (1997). O tempo na biologia. In: Cronobiologia: Princípios e Aplicações. Editora da Universidade de São Paulo, São Paulo, SP, Brazil, 17-21.

18. Mancia G (1980). Autonomic modulation of the cardiovascular system during sleep. New England Journal of Medicine, 328: 347-349.

19. Sunquist ME \& Montgomery GG (1973). Activity patterns and rates of movement of two-toed and three-toed sloths (Cholepus hoffmani and Bradypus infuscatus). Journal of Mammalogy, 4: 946-954. 